\title{
LEVANTAMENTO DAS MANIFESTAÇÕES PATOLÓGICAS COM APLICAÇÃO DO GUT: ESTUDO DE CASO NO TERMINAL RODOVIÁRIO DE CAXIAS-MA
}

\author{
ARAÚJO, ROMÁRIO SALAZAR \\ Engenheiro Civil \\ UniFacema \\ Maranhão; Brasil \\ guimaraes03ms@gmail.com
}

\author{
GUIMARÃES, MARIANA SILVA \\ Engenheira Civil \\ UniFacema \\ Maranhão; Brasil \\ guimaraes03ms@gmail.com
}

\author{
SOUZA, THIAGO HABACUQUE SILVA \\ Engenheiro Civil \\ UniFacema \\ Maranhão; Brasil \\ thabacuque@gmail.com
}

\author{
SOUZA, TALISSA RAYANNE SILVA \\ Engenheira Civil \\ UniFacema \\ Maranhão; Brasil \\ tatah.rayanne@gmail.com
}

\section{RESUMO}

As edificações ao interagirem com o ambiente externo ao qual estão expostas podem sofrer danos que, ao longo do tempo, causam perda na capacidade da estrutura em suportar as condições para as quais foi concebida. Mesmo que se trate de um processo natural, algumas causas influenciam diretamente, como utilização de material de baixa qualidade e a falta de manutenção periódica. Por essas causas, tem se tornado rotineiro o surgimento de manifestações patológicas, prejudicando o desempenho, a estabilidade e a funcionalidade da estrutura, além do consumo de recursos financeiros em reparações que poderiam ser evitadas. Assim, as manifestações patológicas presentes no Terminal Rodoviário de Caxias-MA motivaram o desenvolvimento deste trabalho, visando levantá-las conhecendo suas quantidades, estabelecendo uma ordem de priorização por meio do método GUT. Após a realização de um vistoria e inspeção visual no Terminal Rodoviário em estudo, este trabalho catalogou as manifestações patológicas, verificando que as principais ocorrências se tratam de descascamento de pintura $(20,73 \%)$, desplacamento de emboço e piso cerâmico $(19,27 \%)$, fissuras trincas e rachaduras (12\%), e manchas de mofo, bolor e fungos (8,36\%). Além disso, observou-se por meio da aplicação do Método GUT que os casos relacionados a fissuras, trincas e rachaduras apresentam maior grau de risco e, consequentemente, maior grau de priorização em sua resolução, comprovando o benefício do auxílio desta ferramenta de planejamento na área estudada.

Palavras-chave: manifestação patológica, engenharia diagnóstica, terminal rodoviário, método GUT.

\section{ABSTRACT}

Buildings when interacting with the external environment to which they are exposed may suffer damage that, over time, cause loss in the ability of the structure to withstand the conditions for which it was conceived. Even if it is a natural process, some causes directly influence, such as the use of low quality material and the lack of periodic maintenance. Because of these causes, the emergence of pathological manifestations has become routine, impairing the performance, stability and functionality of the structure, in addition to the consumption of financial resources in repairs that could be avoided. Thus, the pathological manifestations present in the Caxias-MA Bus Terminal motivated the development of this work, aiming to raise them knowing their quantities, establishing an order of prioritization through the GUT method. After conducting a survey and visual inspection in the Bus Terminal under study, this work catalogued the pathological manifestations, verifying that the main occurrences are paint peeling (20.73\%), emboço and floor peeling ceramic (19.27\%), cracks and cracks (12\%), and stains of mold, mold and fungi (8.36\%). In addition, it was observed through the application of the GUT Method that cases related to cracks, cracks and cracks have a higher degree of risk and, consequently, a higher degree of prioritization in its resolution, proving the benefit of the aid of this planning tool in the studied area.

Keywords: pathological manifestation, diagnostic engineering, bus terminal, GUT method. 


\section{INTRODUÇÃO}

Com o desenvolvimento do Brasil, o número de obras no país teve um aumento, por outro lado com problemas na política e uma insatisfação por parte da população, a respeito de obras mal construídas, a qualidade das mesmas vem sendo discutida cada vez mais pela sociedade, principalmente relacionadas as obras públicas.

Problemas estes que são denominados de manifestações patológicas, que para a engenharia e medicina conceitua como estudo das doenças. Contudo, na área da engenharia é intitulada pelo termo "Patologia das Construções" que tem o objetivo de estudar as origens, causas, mecanismos de ocorrência, manifestações e consequências dos problemas que afetam a edificação e sua vida útil (VIEIRA, 2016).

Diversas são as causas para o aparecimento das manifestações patológicas, sendo que, mal planejamento, execução e utilização incorreta dos materiais são algumas das circunstâncias, por consequência surgem os problemas, que podem ser de determinadas maneiras: fissuras, trincas, bolores e eflorescências e corrosão das armaduras por exemplo.

Dessa forma a Norma de Inspeção Predial Nacional do Instituto Brasileiro de Avaliações e Perícias de EngenhariaIBAPE (2012), aconselha que metodologias técnicas apropriadas como o método de gravidade, urgência e tendênciaGUT, para classificar a ordem de prioridades.

O principal benefício de empregar a Matriz GUT para fins de gerenciamento é que a colaboração oferecida ao gestor permite uma avaliação quantitativa dos problemas em estudo, colocando possível a priorização das ações corretivas e preventivas para a supressão total ou parcial do problema (PERIARD, 2011).

Nesse sentido este estudo teve como problemática: Quais as principais manifestações patológicas que podem ser encontradas no terminal rodoviário de Caxias-MA utilizando o método GUT? Para tal elencou-se os seguintes objetivos: Caracterizar e priorizar as manifestações patológicas encontradas no terminal rodoviário de Caxias-MA aplicando o Método da Matriz de Gravidade, Urgência e Tendência (GUT) assim como realizar vistoria do local, com levantamento do histórico e análise do desempenho do edifício, identificando as principais manifestações patológicas encontradas nas edificações do Terminal Rodoviário (Caxias - MA), na qual se aplica o método da Matriz de Gravidade, Urgência e Tendência na edificação em estudo e caracterizar seus resultados.

\section{REFERENCIAL TEÓRICO}

\subsection{Conceito de manifestação patológicas}

Para Souza e Ripper (1998),as manifestações patológicas das estruturas definem-se como "campo da Engenharia das Construções que se ocupa do estudo das origens, formas de manifestação, consequências e mecanismos de ocorrência das falhas e dos sistemas de degradação das estruturas". Esta parte de engenharia tem sua importância devido à necessidade de prorrogar a vida útil das estruturas.

Também é parecer de Iantas (2010) que manifestação patológica é a mudança estrutural ou funcional que promove a degradação do material, que pode ser de diferentes tipos e ataca diretamente no desempenho da estrutura.

\subsection{Origem e causas das manifestações}

Segundo Helene (1992), os principais fatores responsáveis pelo aparecimento das manifestações patológicas, são: planejamento $40 \%$, execução $28 \%$, materiais $18 \%$, uso $10 \%$ e projeto $4 \%$.

Souza e Ripper (1998) ressaltam sobre as prováveis causas e falhas, ocasionadas por um estudo preliminar deficiente ou anteprojetos equivocados, que podem acontecer nesta fase de projeto, na qual alguns dos erros mais relevantes são divergências entre projetos, especificação inadequada de materiais e erros de dimensionamento.

Além disso, na fase de execução da obra, o construtor deve ficar em alerta para cada seleção, os materiais utilizados devem obedecer às especificações de projeto e as exigências de qualidade prescritos nas Normas Brasileiras. 
Para Vieira (2016), se não houver um entendimento preciso, os aparecimentos de manifestações patológicas podem surgir. Dessa forma o construtor deve-se ter o cuidado na escolha das soluções técnicas apropriadas e o controle das diversas tarefas no processo de construção.

Dentro das concepções de Souza e Ripper (1998) apontam que a maior parte das falhas nas estruturas no processo de execução está ligada a pouca qualificação da mão de obra utilizada, na qual se considera um dos agravantes principais para o surgimento de manifestações patológicas da construção, ainda constatam que a presença de um responsável técnico acompanhando uma obra, evita erros em que afetam a durabilidade da edificação.

\subsection{Método GUT}

Para definir prioridades, dadas as várias alternativas de ação, orienta-se que utilize a ferramenta do método GUT, onde o mesmo tende a responder os seguintes questionamentos: "O que deve ser feito primeiro? " Ou "Por onde começar?". Meireles (2001) afirma que afim de responder essas perguntas, pois tem como alcance classificar a importância das ações, levando em conta a gravidade, a urgência e a tendência do caso, escolhendo assim uma decisão mais cômoda e menos desfavorável a situação.

Encontram-se a disposição diversos métodos para avaliação de riscos que podem ser aplicados. Contudo, destaca-se um método, elaborado por Verzola, Marchiori e Aragon (2014), que se ajusta ao método GUT (KEPNER; TREGOE, 1991) para inspeção Predial. Os inspetores devem classificar os riscos das anomalias e falhas diagnosticadas nas edificações, com relação à sua criticidade/gravidade, para que possa determinar as prioridades com relação à medida que precisarão ser efetuadas para sanear os problemas.

A inspeção predial, quando se utiliza o método GUT, são atribuídas notas que variam de 1 a 5 , em uma ordem crescente, sendo o 1 o menos grave e o 5 o mais grave. Ao final da atribuição de notas para os problemas é calculado o produto, através da Equação (I).

Onde,

$$
\mathrm{P}=\mathrm{G} \times \mathrm{U} \times \mathrm{T}
$$

P - Pontuação final;

G - Gravidade, variando de 1 a 5 ;

U - Urgência, variando de 1 a 5 ;

G - Gravidade, variando de 1 a 5 .

O resultado definirá qual o grau de prioridade daquele problema, conforme ilustra o quadro 01. 
Quadro 01 - Método GUT aplicado a inspeção predial

\begin{tabular}{|c|c|c|c|c|}
\hline Valor & Gravidade $(\mathrm{G})$ & Urgência (U) & Tendência $(\mathrm{T})$ & GxUxT \\
\hline 1 & $\begin{array}{l}\text { Nenhum risco à saúde, à integridade física dos } \\
\text { usuários, ao meio ambiente ou ao edifício. } \\
\text { Mínima depreciação do patrimônio. Eventuais } \\
\text { trocas de componentes, nenhum } \\
\text { comprometimento do valor imobiliário. }\end{array}$ & $\begin{array}{c}\text { Não tem } \\
\text { pressa }\end{array}$ & Não vai piorar & \\
\hline 2 & $\begin{array}{l}\text { Sem risco à integridade física dos usuários, sem } \\
\text { risco ao meio ambiente, pequenos incômodos } \\
\text { estéticos ou de utilização, pequenas } \\
\text { substituições de componentes ou sistemas, } \\
\text { reparos de manutenção planejada para } \\
\text { recuperação ou prolongamento de vida } \\
\text { útil. Prejuízo financeiro pequeno. }\end{array}$ & $\begin{array}{l}\text { Pode esperar } \\
\text { um pouco }\end{array}$ & $\begin{array}{l}\text { Vai piorar a } \\
\text { longo prazo }\end{array}$ & \\
\hline 3 & $\begin{array}{l}\text { Risco à saúde dos usuários, desconfortos na } \\
\text { utilização dos sistemas, deterioração passível de } \\
\text { restauração/reparo, podendo provocar perda de } \\
\text { funcionalidade com prejuízo à operação direta } \\
\text { de sistemas ou componentes. Danos ao meio } \\
\text { ambiente passíveis de reparo. Prejuízo } \\
\text { financeiro médio. }\end{array}$ & $\begin{array}{l}\text { O mais cedo } \\
\text { possível }\end{array}$ & $\begin{array}{l}\text { Vai piorar em } \\
\text { médio prazo }\end{array}$ & \\
\hline 4 & $\begin{array}{l}\text { Risco de ferimentos aos usuários, danos } \\
\text { reversíveis ao meio ambiente ou ao edifício. } \\
\text { Impacto recuperável com o comprometimento } \\
\text { parcial do desempenho e funcionalidade (vida } \\
\text { útil) do sistema que afeta parcialmente a saúde } \\
\text { dos usuários ou o meio ambiente. Prejuízo } \\
\text { financeiro alto. }\end{array}$ & Urgente & $\begin{array}{l}\text { Vai piorar em } \\
\text { pouco tempo }\end{array}$ & \\
\hline 5 & $\begin{array}{l}\text { Risco de morte, risco de desabamento/colapso } \\
\text { pontual ou generalizado, iminência de Incêndio, } \\
\text { impacto irrecuperável com perda excessiva do } \\
\text { desempenho e funcionalidade, } \\
\text { comprometimento irrecuperável da vida útil do } \\
\text { sistema causando danos grave à saúde dos } \\
\text { usuários ou ao meio ambiente. Prejuízo } \\
\text { financeiro muito alto. }\end{array}$ & $\begin{array}{l}\text { Ação } \\
\text { imediata }\end{array}$ & $\begin{array}{l}\text { Vai piorar } \\
\text { rapidamente }\end{array}$ & \\
\hline
\end{tabular}

Após apoio dos autores supracitados e realização da pesquisa bibliográfica, partiremos para os materiais e métodos que serão utilizados no estudo de caso.

\section{MATERIAIS E MÉTODOS}

\subsection{Tipos de estudo}

Este trabalho utilizou a classificação de pesquisa apresentada por Silveira e Gerhardt (2009), onde foi classificada quanto a abordagem, natureza, objetivos e procedimentos.

Em relação a abordagem, a pesquisa se classifica como qualitativa, no que concerne à natureza é uma pesquisa aplicada, no tocante aos objetivos, a pesquisa se configura como descritiva, quanto aos procedimentos, a pesquisa classifica-se como bibliográfica e estudo de caso.

\subsection{Local do estudo}

A cidade onde foi desenvolvida a pesquisa foi Caxias-MA, a quinta mais populosa cidade do estado com população de 162.657 habitantes, área de 5.150, $667 \mathrm{~km}^{2}$, o que a torna a terceira maior cidade do Maranhão. É um dos maiores 
centros econômicos do estado graças a seu grande desempenho industrial e um importante centro político, econômico e populacional do estado do Maranhão (IBGE, 2017).

A edificação em análise foi o Terminal Rodoviário Nachor Carvalho inaugurado em 07 de setembro de 1996 , constituído como relevante polo gerador de viagens, localizado em uma das principais avenidas da cidade, tendo em sua volta se localizam agências de viagens, concessionárias, postos de gasolina, e margeando a BR - 316, conforme as figuras 01 e 02 .

Figura 02 - Fachada do Terminal Rodoviário Nachor Carvalho da cidade de Caxias-MA

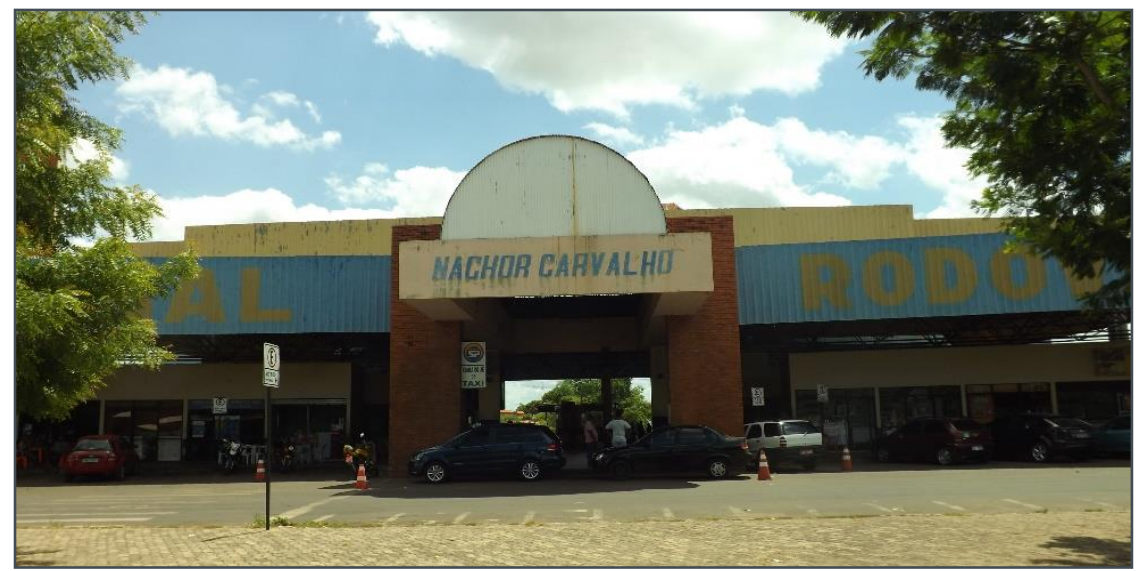

\subsection{Coleta de dados}

Para obter fundamentação teórica e avanço dos objetivos, inicialmente foi feita uma revisão bibliográfica referente as manifestações patológicas, demostrando a importância do tema e as manifestações típicas referentes ao material avaliado. Além disso, foi realizado uma análise bibliográfica sobre a Matriz GUT, indicando sua serventia em diversas áreas e as vantagens da sua utilização.

Em conjunto à revisão bibliográfica, foi utilizada a técnica não destrutiva de inspeção visual para as avaliações das características visuais em função da presença de manifestações patológicas, coletando dados e registros fotográficos das mesmas. A inspeção do local para colhimento das informações, foi realizado entre os meses de junho e agosto.

De forma a organizar as informações colhidas em campo conforme o embasamento teórico contido nesse trabalho, foi elaborada um quadro contendo os dados referentes a cada dano patológico e sua respectiva quantidade e porcentagem, conforme tabela 02 .

Tabela 02 - Frequência por tipo de manifestação patológica

\begin{tabular}{c|c|c}
\hline Tipo & Quantidade & Porcentagem \\
\hline Manifestação 01 & & \\
\hline Manifestação 02 & & \\
\hline$\ldots$ & & \\
\hline
\end{tabular}

Logo após a identificação das principais manifestações patológicas foram feitas análises através do método GUT. Para isso, foi elaborada uma matriz para se aplicar o método, classificando cada manifestação de acordo com as variáveis apresentadas na revisão bibliográfica deste trabalho, de acordo com a tabela 03 .

Tabela 03 - Matriz de aplicação pelo método GUT.

\begin{tabular}{c|c|c|c|c|c}
\hline $\begin{array}{c}\text { Problema } \\
\text { patológico }\end{array}$ & $\mathrm{G}$ & $\mathrm{U}$ & $\mathrm{T}$ & GUT & $\begin{array}{c}\text { Grau de } \\
\text { priorização }\end{array}$ \\
\hline Manifestação 01 & & & & & \\
\hline Manifestação 02 & & & & & \\
\hline$\ldots$ & & & & & \\
\hline
\end{tabular}




\subsection{Equipamentos utilizados}

Para realizar um ensaio de inspeção visual é necessária a utilização de alguns equipamentos básicos que auxiliem neste processo. Para efetuar o levantamento desses dados foram utilizados: equipamento para registro fotográfico (celular e câmera fotográfica profissional); caneta; lápis e prancheta.

\section{APRESENTAÇÃO DOS RESULTADOS}

Os resultados foram classificados de acordo com as principais manifestações patológicas encontradas, como: descascamento de pintura; desplacamento de emboço e piso cerâmico; fissura, trinca e rachadura; mofo, bolor e fungos; das instalações hidrossanitária e elétrica; corrosão, lixiviação; em pavimento asfáltico; bolhas; recalque e outros.

A tabela 04 mostra o resultado do levantamento realizado, que fora possível encontrar avarias em 275 pontos distintos, de variadas formas e tamanhos, na mesma tabela é apresentada a quantidade de cada manifestação patológica assim como sua porcentagem, a contagem foi realizada através de registros fotográficos, e pôde-se atentar que para cada imagem analisada havia inúmeras degradações existentes, desta forma é possível observar que as manifestações que apareceram com mais frequência na edificação estudada foram o descascamento da pintura, e com destaque também para: desplacamento de emboço e piso cerâmico, fissuras, trincas e rachaduras.

Tabela 04 - Frequência por tipo de manifestação patológica

\begin{tabular}{|c|c|c|}
\hline Tipo & Quantidade & Porcentagem \\
\hline Descascamento da pintura & 57 & $20,73 \%$ \\
\hline Desplacamento (piso cerâmico e emboço) & 53 & $19,27 \%$ \\
\hline Fissuras, trincas e rachaduras & 33 & $12,00 \%$ \\
\hline Mofo, bolor e fungos & 23 & $8,36 \%$ \\
\hline Hidrossanitária & 22 & $8,00 \%$ \\
\hline Corrosão & 21 & $7,64 \%$ \\
\hline Elétrica & 18 & $6,55 \%$ \\
\hline Lixiviação & 10 & $3,64 \%$ \\
\hline Infiltração & 10 & $3,64 \%$ \\
\hline Pavimento asfáltico & 9 & $3,27 \%$ \\
\hline Bolhas & 4 & $1,45 \%$ \\
\hline Recalque & 3 & $1,09 \%$ \\
\hline Outros (cupim, vegetação e junta de dilatação) & 12 & $4,36 \%$ \\
\hline Total & 275 & $100 \%$ \\
\hline
\end{tabular}

A seguir serão expostas algumas imagens do registro fotográfico com base nos diversos tipos de manifestação patológica encontrada.

$\mathrm{Na}$ pintura do terminal rodoviário foram encontradas a maioria das manifestações patológicas, o descascamento da pintura foi identificado em 57 locais diferentes, ocupando assim a primeira posição, correspondendo a 20,73\%. Paredes, pilares, vigas e forro apresentam esse tipo de dano, a figura 03 retrata essa situação.

Figura 03 - Descascamento da pintura: em alvenaria (A), em pilar (B) e em forro (C).

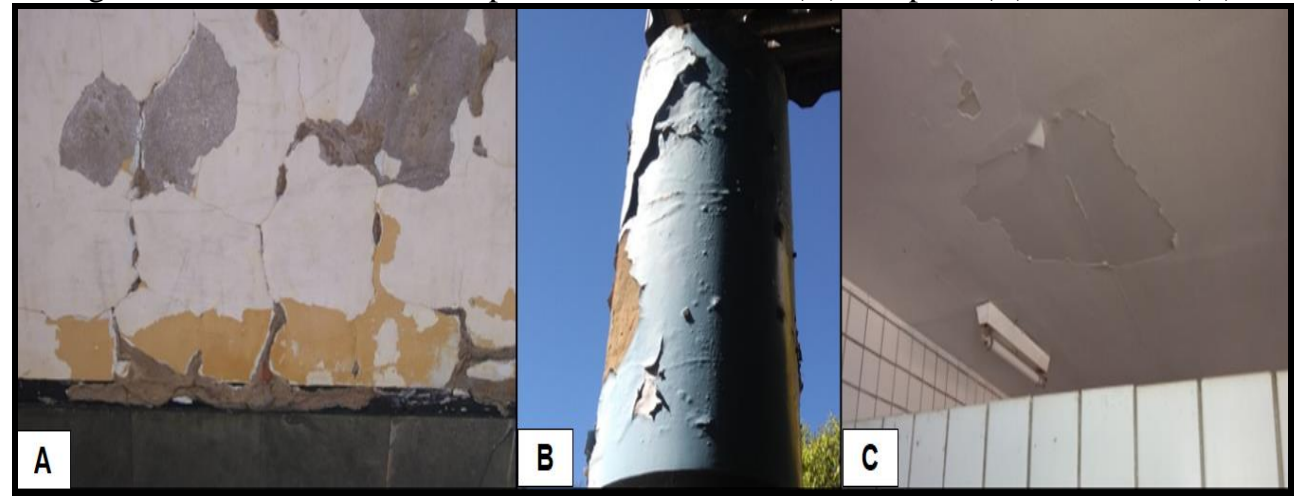


No tocante ao desplacamento tanto de emboço quanto do piso cerâmico foram detectados 53 pontos na edificação, equivalendo a $19,27 \%$, sendo as paredes, pisos e pilares os principais locais em que se encontrava, como mostra a figura 04.

Figura 04 - Desplacamento de: emboço em alvenaria (A), emboço em pilar (B), placa cerâmica em alvenaria (C)

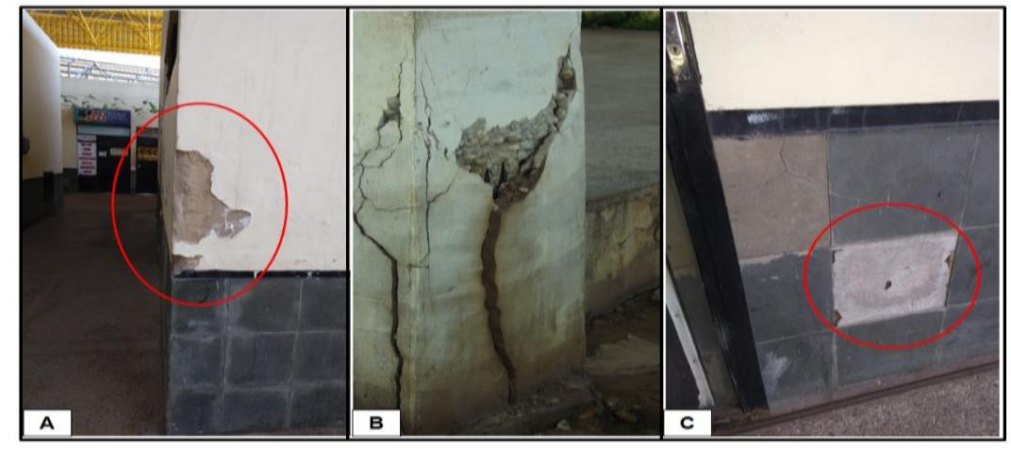

$\mathrm{O}$ estudo de caso, foram detectadas fissuras, trincas e rachaduras de variadas formas e tamanhos, em 33 locais precisamente, presentes em pisos, paredes, pilares, viga e mureta, correspondendo a $12 \%$, a figura 05 retrata a condição em que se encontra a estrutura do terminal rodoviário.

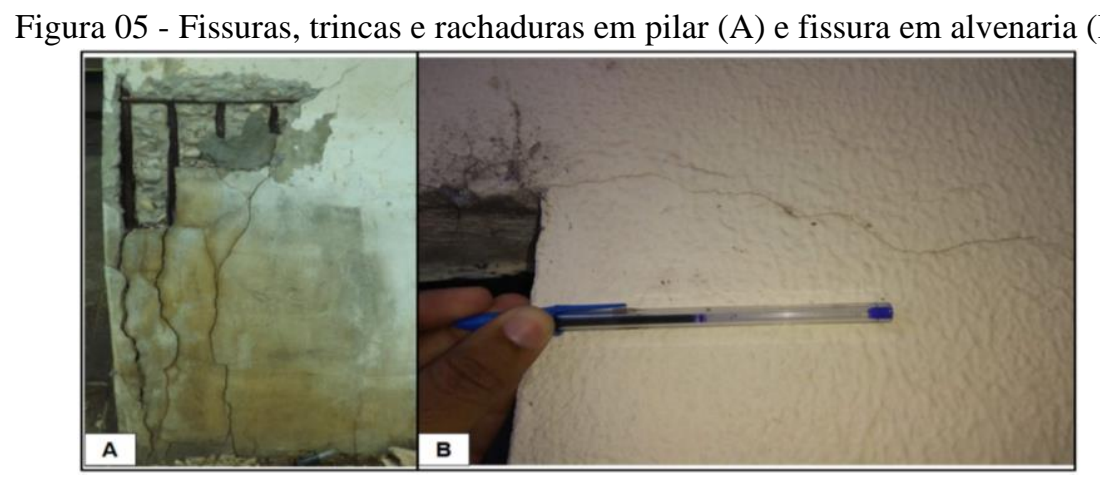

Em relação as manifestações patológicas como mofo, bolor e fungos, foram identificados em 23 pontos distintos, encontrados em paredes, pilares e vigas da edificação, correspondendo a 8,36\%, conforme a tabela 03 . A figura 06 mostra o estado encontrado da estrutura do terminal rodoviário.

Figura 06 - Mofo, bolor e fungos: em alvenaria interna (A) e externa (B) e em pilar (C).

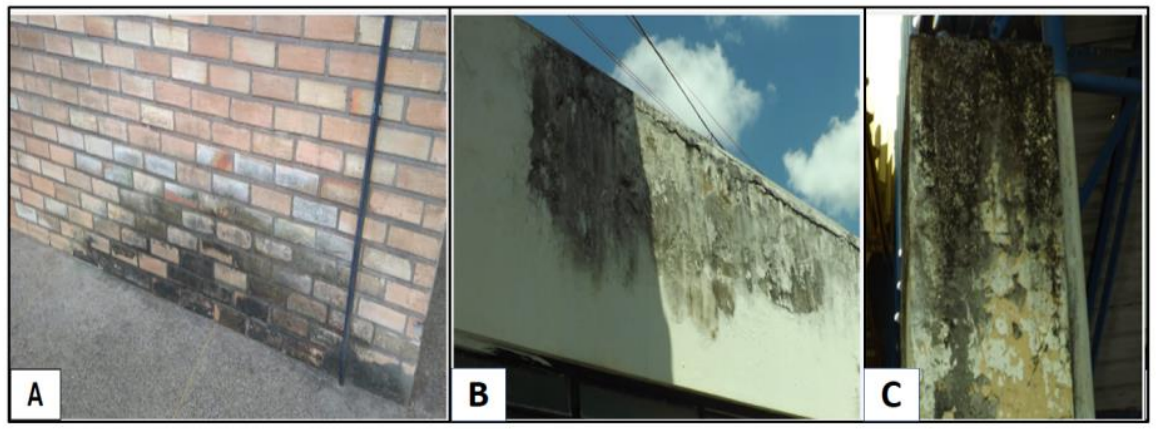

Fonte: Autor (2018).

A respeito da presença das manifestações patológicas em instalações hidrossanitárias, foram encontrados 22 locais com danos, o equivalente a 8\%, em alguns aparelhos sanitários pôde-se notar a ausência das tampas dos vasos sanitários, tubulações de PVC encontram-se exposta ao sol e à ação de intempéries, além disso encontrou-se um registro sem nenhuma proteção ocasionando assim a sua degradação. A respeito dos danos das instalações elétricas foram observados em 18 locais correspondendo a 6,55\%, parte da rede elétrica se encontra aparente, exposta a intempéries, 
com extensões precárias e parte dos pontos de tomada e interruptores encontram-se inoperantes, observa-se partes dos danos na figura 07.

Figura 07 - Degradação de instalação: hidráulica (A) e elétrica (B).

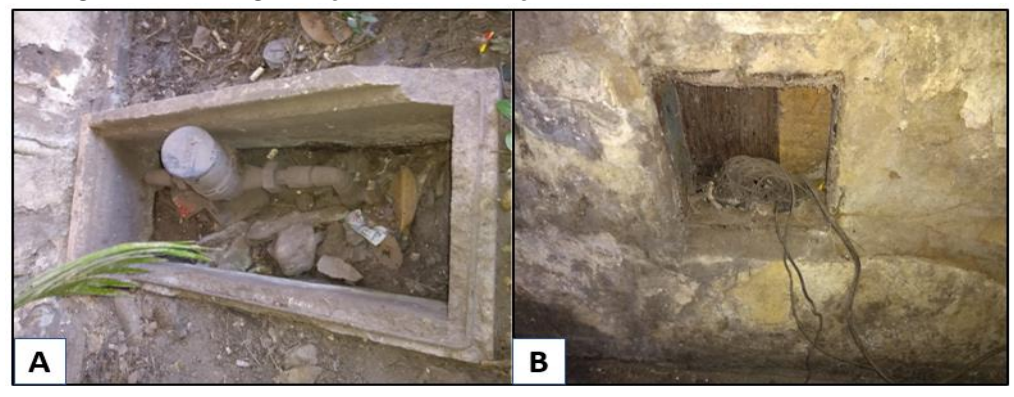

$\mathrm{Na}$ inspeção realizada, foram identificadas 21 locais em que apresentava corrosão, equivalendo a 7,64\%. Tais corrosões foram encontradas na cobertura, pilares e esquadrias, tendo como observação a vistoria realizada em cobertura, pois se teve acesso somente ao ambiente interno, a figura 08 mostra o estado encontrado na estrutura do estudo de caso.

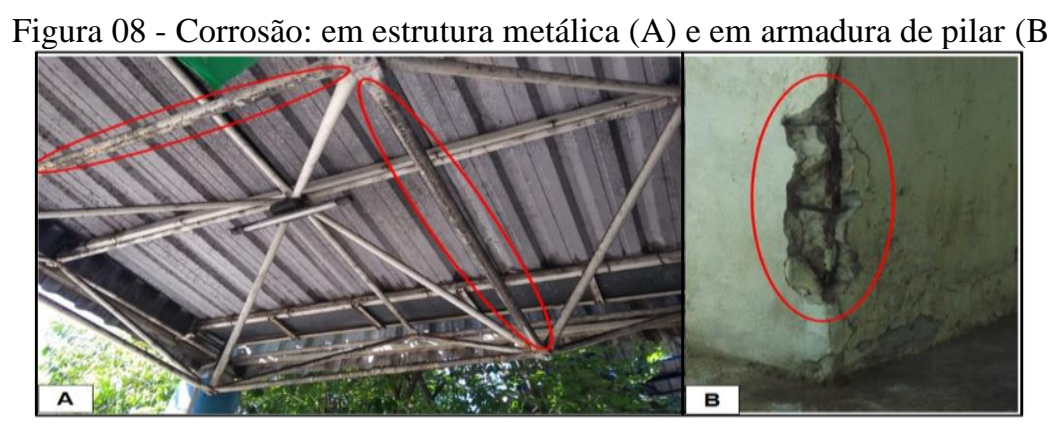

No que diz respeito a desconformidade provocada pela lixiviação, foi observada a sua ocorrência em 10 locais da edificação, em elementos estruturais como pilares e vigas, assim como na alvenaria, correspondendo a 3,64\%, como mostra a figura 09 .

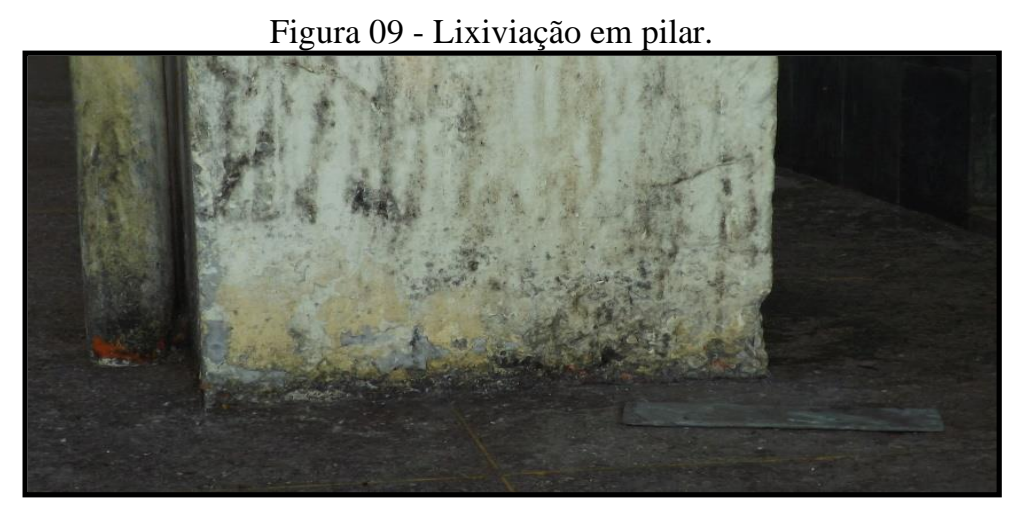

No tocante à infiltração foi observada em 10 locais distintos, em alvenaria, pilares e caixa d'água, o que corresponde a $3,64 \%$, a figura 10 estará retratando essa situação. 
Figura 10 - Infiltração: (A) em viga e (B) em alvenaria

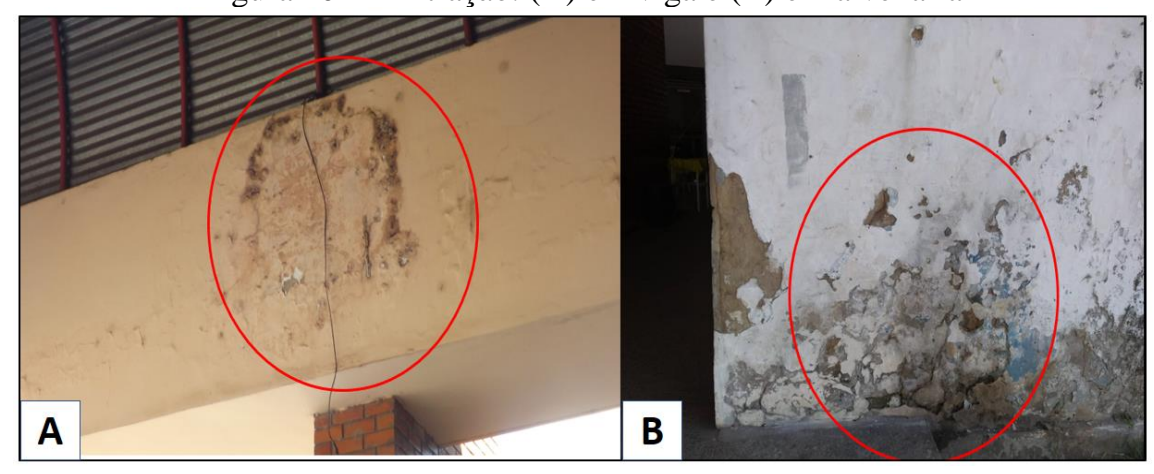

Durante inspeção visual também pôde-se observar deformações no pavimento asfáltico do ambiente externo do terminal rodoviário, onde foram encontrados 9 tipos de manifestações patológicas, tais como trinca tipo couro de jacaré, panelas e afundamento plástico provocados pelas rodas dos ônibus, conforme mostra a figura 11.

Figura 11 - Afundamento plástico (A) e trinca tipo couro de jacaré (B).

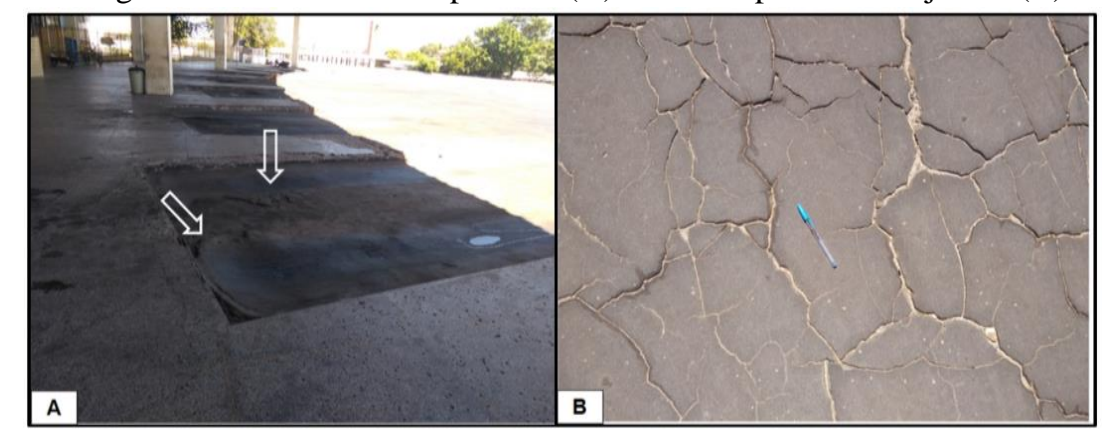

No que tange sobre manifestação patológica, bolhas, foram encontradas 4 locais, sendo estes, paredes e vigas, que correspondem a $1,45 \%$, como mostra a figura 12 .

Figura 12 - Bolhas: em viga (A) e parede (B).

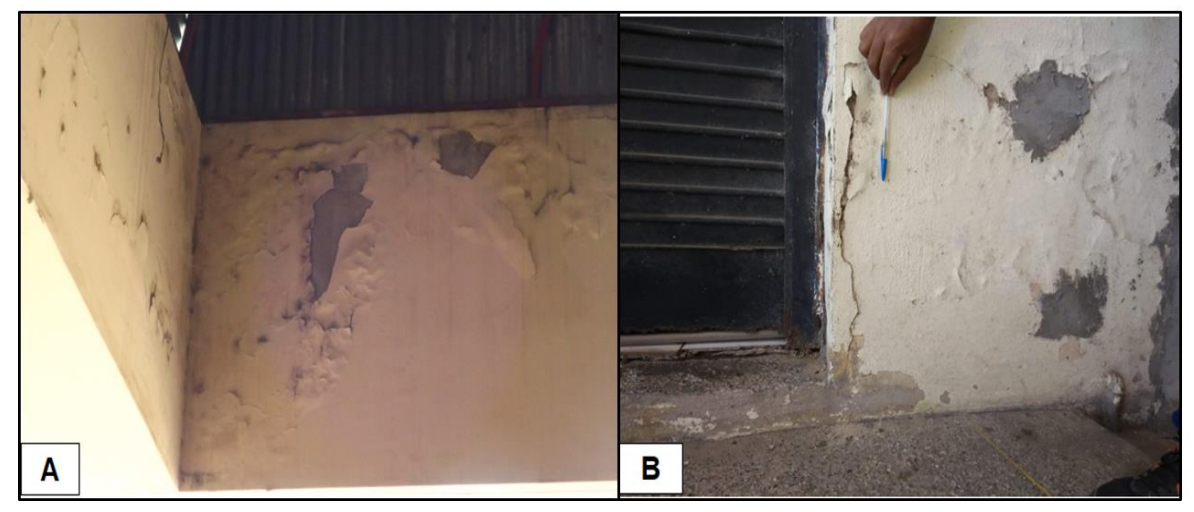

No decorrer da vistoria realizada no terminal, pôde-se observar, tanto nos banheiros masculino quanto feminino, a presença de recalque em alguns lugares do piso cerâmico, como pode-se analisar na figura 13.

Figura 13 - Recalque diferencial em banheiro: (A) masculino e (B) feminino.

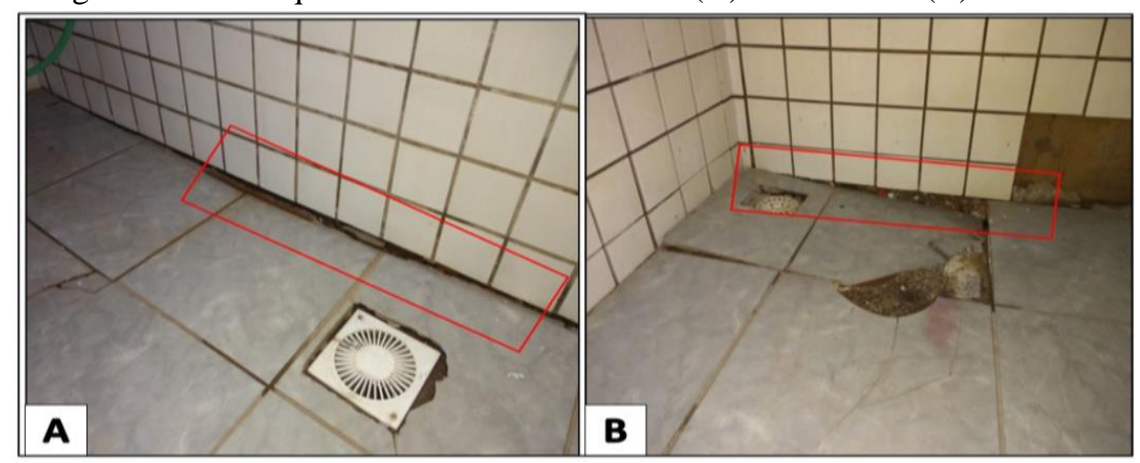


Após apresentação das manifestações identificadas em inspeção feita in loco, partiremos para aplicação do método GUT, onde foi feito pontuação quanto a gravidade, urgência e tendência, de modo a facilitar o tratamento de tais anomalias.

Através da tabela 04 apresentada, foram classificadas as manifestações patológicas identificadas no estudo de caso de acordo com as variáveis do método GUT. Os produtos conseguidos através da aplicação do método expressam a análise da problemática de cada manifestação, resultando na seguinte ordem de priorização, de acordo com a tabela 05 .

Tabela 05 - Matriz de aplicação pelo método GUT

\begin{tabular}{l|c|c|c|c|c}
\hline \multicolumn{1}{c}{ Manifestação patológica } & $\mathrm{G}$ & $\mathrm{U}$ & $\mathrm{T}$ & $\mathrm{GUT}$ & Grau de priorização \\
\hline Descascamento da pintura & 2 & 3 & 4 & 24 & $3^{\text {o }}$ \\
\hline Fissuras, trincas e rachaduras & 4 & 5 & 3 & 60 & $1^{\text {o }}$ \\
\hline Mofo, bolor e fungos & 2 & 3 & 2 & 12 & $5^{\text {o }}$ \\
\hline Desplacamento (emboço e piso cerâmico) & 3 & 3 & 4 & 36 & $2^{\text {o }}$ \\
\hline Hidrossanitária & 2 & 2 & 3 & 12 & $5^{\text {o }}$ \\
\hline Corrosão & 3 & 4 & 3 & 36 & $2^{\text {o }}$ \\
\hline Elétrica & 3 & 3 & 2 & 18 & $4^{\text {o }}$ \\
\hline Lixiviação & 2 & 2 & 3 & 12 & $5^{\text {o }}$ \\
\hline Pavimento Asfáltico & 3 & 2 & 2 & 12 & $5^{\text {o }}$ \\
\hline Infiltração & 2 & 3 & 4 & 24 & $3^{\text {o }}$ \\
\hline Recalque & 3 & 2 & 2 & 12 & $5^{\text {o }}$ \\
\hline Bolhas & 1 & 2 & 2 & 4 & $6^{\text {o }}$ \\
\hline
\end{tabular}

Os resultados obtidos após aplicação do método mostram que algumas manifestações patológicas apontam o mesmo grau de prioridade. De forma esclarecer, a tabela 06 dispõe de forma crescente o grau de prioridade em suas resoluções, juntando as manifestações que apresentam a mesma pontuação final.

Tabela 06 - Priorização para resolução das manifestações patológicas

\begin{tabular}{c|c}
\hline Grau de priorização & Manifestação patológica \\
\hline \multirow{2}{*}{$1^{\circ}$} & Fissuras, trincas e rachaduras \\
\hline \multirow{2}{*}{$2^{\circ}$} & Desplacamento (emboço e piso cerâmico) \\
\cline { 2 - 2 } & Corrosão \\
\cline { 2 - 2 } $4^{\circ}$ & Descascamento da pintura \\
\hline \multirow{2}{*}{$5^{\circ}$} & Infiltração \\
\cline { 2 - 2 } & Elétrica \\
\cline { 2 - 2 } & Mofo, bolor e fungos \\
\cline { 2 - 2 } & Hidrossanitária \\
\cline { 2 - 2 } & Lixiviação \\
\hline \multirow{2}{*}{$6^{\circ}$} & Recalque \\
\hline
\end{tabular}

\section{DISCUSSÃO}

No presente estudo houve prevalência do descascamento de pintura resultado similar à de Alves, Medeiros e Barreto (2017), Eduardo, Santos e Nóbrega (2017) que analisaram prédios públicos e mostraram que a maioria das manifestações encontradas correspondia a descascamento de pintura, porém, Silva e Bento (2017) mostraram em estudo realizado em escolas públicas, que na maioria das edificações estudadas a presença mofo e bolor foi a que teve maior incidência.

Com referência a mofo, bolor e fungos corroboram com tal afirmação, o estudo realizado por Cunha et al. (2013) em hospital público e por Eduardo, Santos e Nóbrega (2017), Silva e Bento (2017) que procederam o estudo em uma edificação escolar pública. Os mesmos descrevem que dentre as principais manifestações encontradas nestes ambientes públicos, manchas provenientes de bolor e fungos estavam presentes na edificação. 
Descascamento de pintura, bolhas, mofo, bolor e fungos, correspondem a 30,54\%, sendo as avarias que mais incidem na alvenaria da edificação, isto sugere que esta parte do edifício apresenta uma maior predisposição ao aparecimento destas avarias em função da sua exposição direta a intempéries. Vale ressaltar também que o próprio material utilizado para o revestimento tem uma tendência natural ao favorecimento do aparecimento deste dano. Essas manifestações podem ser ocasionadas por diversos fatores, como pôde-se observar na estrutura, há a ausência de ventilação, iluminação, insolação, umidade e vegetação densa, tais fatores podem ser a causa de tais manifestações patológicas.

A corrosão do concreto armado é um dos principais fatores para surgimento de fissuras, trincas e rachaduras no terminal rodoviário, assim como agente relacionados a umidade são os precursores para desplacamento de emboço e placa cerâmica. No local de estudo, a corrosão é provocada principalmente onde a edificação está inserida, estando a mesma em um ambiente úmido e agressivo, onde pôde-se observar que a cobertura apresenta ferrugem ocorrentes das águas pluviais.

No estudo de caso realizado, a projeção de uma cobertura mal elaborada, vegetação em grandes proporções, falta de manutenção nas instalações hidrossanitárias e elétricas, são um dos principais fatores para ocorrências de tais manifestações supracitadas.

Em referência a aplicação do método GUT percebe-se que fissuras, trincas e rachaduras, que na maioria das vezes são provocadas por causa da corrosão de armadura, estão próximas no grau de prioridade, fazendo com que o método tenha significância exata. Nota-se também que o descascamento da pintura, mesmo aparecendo em maior quantidade, não é prioridade para ser solucionado tão logo.

\section{CONCLUSÃO}

O presente trabalho proporcionou identificar as principais manifestações patológicas presentes no terminal rodoviário de Caxias-MA, edificação pública com mais de 20 anos.

As principais ocorrências tratam-se de descascamento de pintura $(20,73 \%)$, desplacamento de emboço e piso cerâmico $(19,27 \%)$, fissuras trincas e rachaduras $(12 \%)$, e manchas de mofo, bolor e fungos $(8,36 \%)$.

Dessa maneira, diante de tudo que foi exposto, pode-se afirmar que a falta de manutenção é um fator determinante para dar início a degradação de um prédio, causando uma série de manifestações patológicas, ocasionadas por esse fator, como por outros, atrelados a construção, ocupação e alterações realizadas no decorrer dos anos. A reforma do local, que necessita de uma atenção do poder público, faz-se fundamental devido a condição para preservação e condições de uso, principalmente pela importância do local, um dos principais polos geradores da cidade.

No tocante a utilização do método GUT para a definição da ordem de prioridade de resolução entre as avarias encontradas, foi confirmado sua serventia na área de estudo, uma vez que se tornou possível realizar a hierarquização de riscos pertinentes às manifestações patológicas avaliadas. Com posse dos resultados desses procedimentos, poderão ser feitas melhorias quanto ao planejamento estratégico para o setor da instituição responsável pela realização de manutenções.

Por fim, o presente trabalho visa contribuir para um plano de manutenção e conservação das edificações, por meio da proposição de um método de inspeção predial, tomando como base as normas, instruções técnicas e métodos presentes na literatura.

Como sugestão a trabalhos futuros, sugere-se a continuidade desta linha de pesquisa, podendo efetuar a realização de estudo das manifestações patológicas em outras edificações públicas de Caxias - MA e realizar o prognóstico, diagnóstico e a terapêutica para cada manifestação patológica do Terminal Rodoviário em estudo.

\section{REFERÊNCIAS}

ALVES, E. V. C., MEDEIROS, M. K. S., BARRETO, A. M. Análise das manifestações patológicas em fachadas de edifícios públicos na cidade de Angicos-RN. XIII Congresso Internacional sobre Patologia e Reabilitação de Estruturas - CINPAR 2017, Crato-CE, Brasil, setembro 2017. 
CUNHA, B. F. da., ZIMMERMANN, C. C., SILVA, J. P. B. da., ROMAN, R.R., OSTROWSKI, R. A. P. Investigação de manifestações patológicas em patrimônio histórico: estudo de caso do Hospital e Maternidade Carlos Corrêa. IX Congresso Internacional sobre Patologia e Reabilitação de Estruturas - CINPAR 2013, João Pessoa-PB, Brasil, junho 2013.

EDUARDO, A. F., SANTOS, J. E. da S., NÓBREGA M. V. da. Estudo da incidência de manifestações patológicas em uma edificação: caso de uma escola em Angicos/RN. XIII Congresso Internacional sobre Patologia e Reabilitação de Estruturas - CINPAR 2017, Crato-CE, Brasil, setembro 2017.

HELENE, P. Manual para reparo, reforço e proteção de estruturas de concreto. São Paulo, Pini: 1992.

IANTAS, L. C. Estudo de caso: análise de patologias estruturais em edificação de gestão pública. 2010.58 f. Trabalho de conclusão de curso - Universidade Federal do Paraná, Curitiba, 2010.

IBAPE/SP. INSTITUTO BRASILEIRO DE AVALIAÇÕES E PERÍCIAS DE ENGENHARIA DE SÃO PAULO -. Inspeção Predial a Saúde dos Edifícios. São Paulo. 2012.

IBGE - Instituto Brasileiro de Geografia e Estatística. Censo Demográfico 2017.

KEPNER, C., \& TREGOE, B. (1991). O Novo Administrador Racional. São Paulo: Makron Books.

MEIRELES, M. Ferramentas administrativas para identificar, observas e analisar problemas. 1. ed. São Paulo: Art \& Ciência, 2001.

PERIARD, G. Matriz GUT: Guia Completo. 2011.

SILVA, D., BENTO, A. Manifestações patológicas em ambientes escolares: estudo de caso das escolas de referência de Pernambuco. XIII Congresso Internacional sobre Patologia e Reabilitação de Estruturas - CINPAR 2017, Crato-CE, Brasil, setembro 2017.

SILVEIRA, D.T; GERHARDT, F.P. A pesquisa científica. Métodos de Pesquisa.1.ed. Rio Grande do Sul: UFRGS, 2009 .

SOUZA, V. C.; RIPPER, T. Patologia, recuperação e reforço de estruturas de concreto. São Paulo: Pini, 1998.

VERZOLA, S. N.; MARCHIORI, F.F.; ARAGON, J.O. Proposta de lista de verificação para inspeção predial x urgência das manutenções. XV Encontro Nacional de Tecnologia do ambiente Construído - ENTAC. Maceió, 2014.

VIEIRA, M. A. Patologias Construtivas: conceito, Origens e Método de Tratamento. Revista Especialize On-Line IPOG. Goiânia, $12^{\mathrm{a}}$ ed, n. 012, jan-dez/2016. 